\title{
Effectiveness of e-health systems in improving hypertension management and awareness: a systematic review
}

\author{
Mohamed Alotaibi ${ }^{1}$ and Mohammad Ammad uddin ${ }^{2 *}$ \\ ${ }^{1}$ College of Computer and Information Technology, University of Tabuk, Saudi Arabia \\ ${ }^{2}$ SNCS Research Centre University of Tabuk, Saudi Arabia \\ [e-mail :mmalotaibi@ut.edu.sa,mashfaq@ut.edu.sa] \\ * Corresponding author: Mohammad Ammad uddin
}

Received March 2, 2021; revised May 7, 2021; revised August 20, 2021; revised October 13, 2021; accepted November 8, 2021; published January 31, 2022

\begin{abstract}
Recent studies have focused on self-management of hypertension using smart devices (cellular phones, tablets, watches). It has proven to be an effective tool for early detection and control of high Blood Pressure (BP) without affecting patients' daily routines. This systematic review surveys the existing self-monitoring systems, evaluate their effectiveness and compares the different approaches. We investigated the current systems in terms of various attributes, including methods used, sample size, type of investigation, inputs/ outputs, rate of success in controlling BP, group of users with higher response rate and beneficiaries, acceptability, and adherence to the system. We identified some limitations, shortcomings, and gaps in the research conducted recently studying the impact of mobile technology on managing hypertension. These shortcomings can generate future research opportunities and enable it to become more realistic and adaptive. We recommended including more observable factors and human behaviors that affect BP. Furthermore, we suggested that vital monitoring/logging and medication tuning are insufficient to improve hypertension control. There is also a need to observe and alter patient behavior and lifestyles.
\end{abstract}

Keywords: Hypertension Monitoring, Blood Pressure Control, Mobile Application for BP monitoring. 


\section{Introduction}

Global health dynamics have changed significantly over the past decade. Several factors have contributed to these changes, including climate change, economic development, and lifestyles. The number of people with diabetes, cancer, and cardiovascular diseases has increased during this period. As per the WHO report published in 2020 [1], 12\% of the global population, about one billion people, has been diagnosed with hypertension, causing approximately 7.5 million mortality annually. Many people do not realize they have hypertension since it has very few noticeable symptoms, hence the "silent killer" epithet. As a result, most patients are diagnosed with hypertension later or have caused other fatal diseases like renal impairment, stroke, coronary heart attack, or heart failure.

The patient's age correlates the abnormal blood pressure and the higher risk of getting other related complications. An earlier WHO study [2] conducted in 2014 says that nearly onefifth of young adults at least 18 years old were also diagnosed with high blood pressure. The number of deaths caused by high blood pressure is relatively high in third-world countries due to patient mismanagement. Moreover, $46 \%$ of the population of these countries is diagnosed with hypertension.

There are many patients with high blood pressure in first-world countries, as well. However, due to better health management in these countries, the percentage is slightly lower than in developing countries: In the USA and Europe, for instance, the percentage of people diagnosed with hypertension is $38 \%$ and $36 \%$, respectively [1].

The situation is similar in Asian countries, like the Kingdom of Saudi Arabia. As we said, the leading cause is the mismanagement of health care information received by the public. In the Gulf countries, for instance, data is not as accessible as in European countries. In some Asian countries, such information is not accessible at all. A survey was conducted on 10,735 citizens of Saudi Arabia who were at least 15 years old to address this issue. The objective was to raise public awareness about the risk of getting hypertension. Survey participants were tested and interviewed to determine whether they had developed high blood pressure and were they aware of it and its consequences. The indicators used during the survey included symptoms, causes, risk factors, available management options, and factors of regression [3].

Since the international medical guidelines widely accept the utilization of home BP management procedures as a valid method for hypertension control, the number of mobile applications that enable their users to measure their blood pressure has increased over the past twenty years [4].

During that period, the number of mobile phone users increased from year to year. Mobile phones can now be used for various purposes in addition to communication. One of the noncommunication applications of mobile phones is health. It has been shown that the advancement of mobile technology is capable of helping health practitioners deliver accurate services to their patients and the public in general, particularly in terms of chronic disease management. The practice of utilizing mobile technology to provide medical services is called mobile health (m-health). As noted by Istepanian, "one important emerging m-health scenario is the use of mobile phones, iPods, iPads and other portable devices for the prevention and management of chronic condition" [4], [5], [6]. 
Due to the recent increase in mobile technology utilization in the medical field, researchers have been studying its impact on managing diseases, especially chronic disease [7]. An example of such an application is a mobile diabetes management system that may help users to diagnose and effectively manage their type 1 and type 2 diabetes, which allows them to enjoy a better quality of life [8]-[10].

As we have seen in the survey that mobile health management is a hot topic of research in this decade and a huge number of proposals are initiated to manage different diseases. As a result, many mobile applications are developed and launched to improve the quality of human health. The objective of this survey was to investigate that either these applications are successful in server their purposes and really helpful to manage and control targeted diseases. We also wanted to highlight the shortcomings and limitations of these applications that can be improved in the future to get better results.

To achieve these objectives we investigated some clinical surveys that were conducted to evaluate the performance of these mobiles applications. Finally, we found some shortcomings of these surveys that should be addressed to have better knowledge in the future and we also highlighted the inadequacies of different applications and we provided some recommendations to make them more realistic and aligned with the targeted disease specifications.

The methodology we adopted to conduct this survey is described in the next section.

\section{Methodology}

This survey was conducted in June 2020. Different research databases like PubMed, IEEE Explore, and Scopus were searched to find the proposed systems that are using mobile technology (SMS, web-based with the use of mobile technology, or mobile application) to manage hypertension. In the first stage, the abstracts of all the queried papers were reviewed to determine how many patients cases were reported in each article. Full versions of the research papers of our interest were obtained from the digital library of the University of Tabuk. The research papers were shortlisted to download based on keywords, including proxy health outcomes, health outcomes, mobile health usability, treatment management process, patient adherence and costs. If the abstract of any paper contained any information about the use of mobile health technology for hypertension, the author read the whole article in depth in the second stage and summarized the paper in the form of a log including title, study design, types and number of participants as shown in Table 1. Finally, we archived the article appropriately for future reference by assigning a unique number. Preferred Reporting Items for Systematic Reviews and Meta-Analyses (PRISMA) flow diagram is given below Fig. 1.

\section{Literature Comparative Study}

Twenty-two papers fit our criteria, as shown in Table 1. Two were found in IEEE, 14 were found in PubMed, and others in Scopus. Moreover, about half of the studies (11) followed the randomized control trial (RCT) design. Whereas four studies used mixed methodologies of the comparative, controlled, multicenter, randomized cluster. In comparison, only one qualitative study was found. We also noticed that some studies were based on proof-ofconcept protocol, and others used the cohort method for observation. 


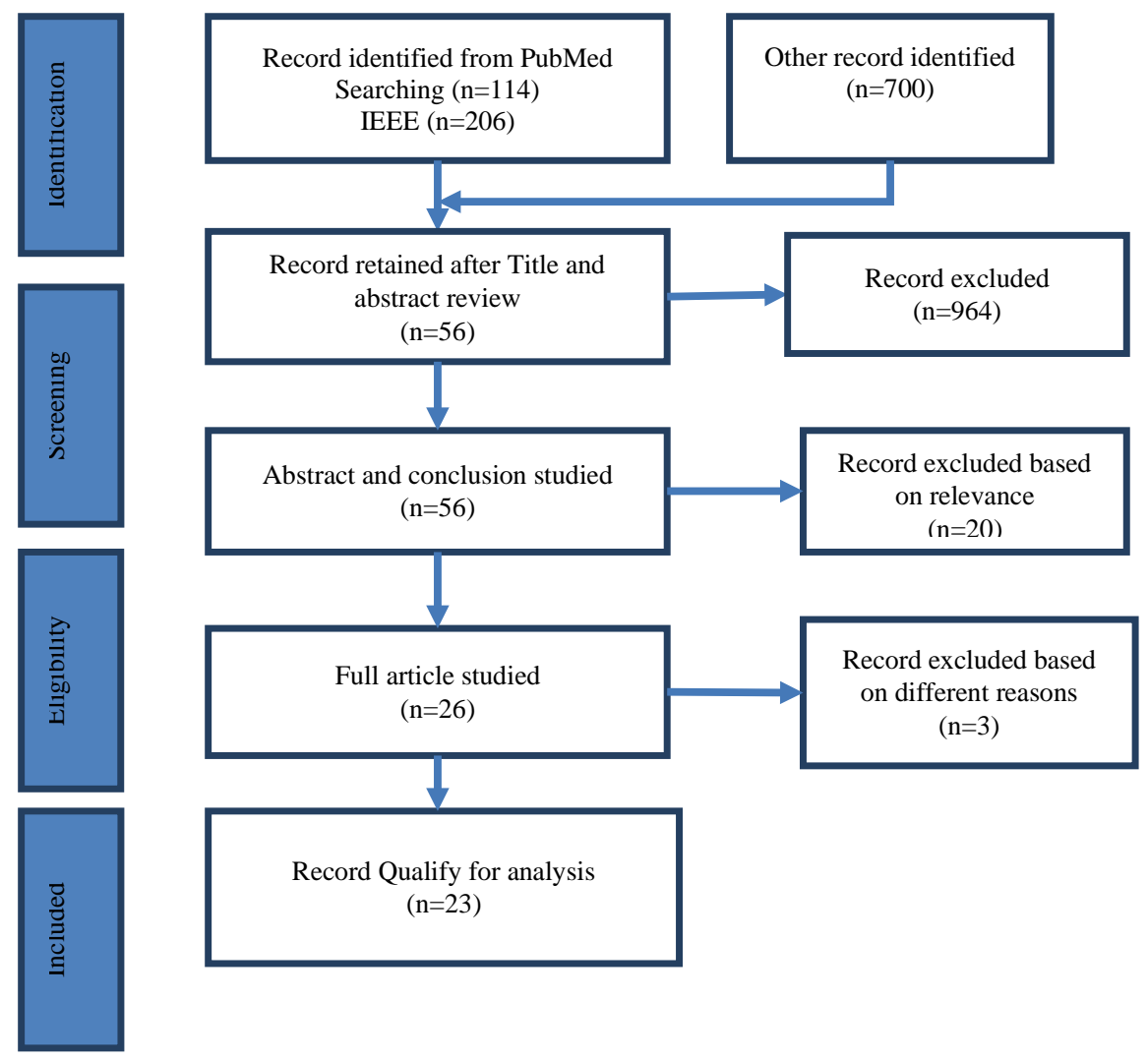

Fig. 1. PRISMA flow diagram for the review of mobile technology for hypertension management

Table 1. List of studies that fit the study criteria

\begin{tabular}{|c|c|c|c|c|c|c|}
\hline \# & 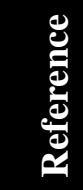 & 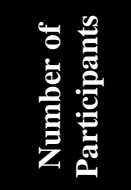 & 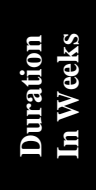 & 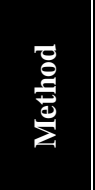 & 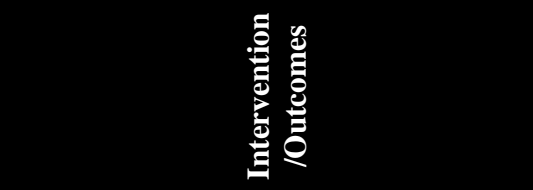 & 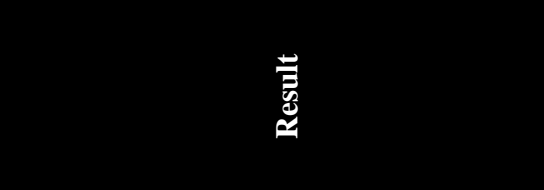 \\
\hline 1 & [11] & 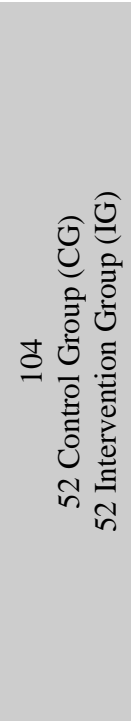 & 16 & 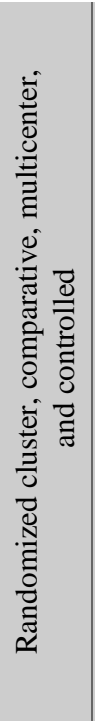 & $\begin{array}{l}\text { 1- In the CG, the physician instructs the } \\
\text { patients through their mobile } \\
\text { devices. } \\
\text { 2- Patients in the IG received physician } \\
\text { advice to continuously adjust the } \\
\text { timing and quantity of medications } \\
\text { for a specific period (in months). } \\
\text { 3- The frequency of medications } \\
\text { (tablets) and BP condition was noted } \\
\text { at the start of the study and reviewed } \\
\text { after } 1,3 \text {, and } 6 \text { months. } \\
\text { 4- The percentage and average of user } \\
\text { compliance to the system and degree } \\
\text { of hypertension control were } \\
\text { measured and compared. } \\
\text { 5- The relative and absolute patient } \\
\text { health risk was calculated and } \\
\text { revised. } \\
\text { 6- Treatment plans were made for } \\
\text { individuals. }\end{array}$ & $\begin{array}{l}\text { The data were collected from } 104 \\
\text { individuals, with an equal number of } \\
\text { users in the CG and IG. The observations } \\
\text { were as follows: } \\
\text { 1. The compliance percentage in the CG } \\
\text { was } 85.1 \% \text { (confidence interval (CI) } \\
74.9 \%-95.3 \% \text { ), the overall compliance } \\
\text { was } 85.7 \% \text { (CI } 70.5 \%-100.9 \% \text { ), and } \\
\text { the compliance in the IG was } 84.4 \% \\
\text { (CI } 70.7 \%-95.3 \% \text {; P=NS (Not } \\
\text { Significant)). } \\
\text { 2. The average percentage compliance } \\
\text { was } 90.2 \% \pm 16.3 \% \text { in the CG and } \\
88.1 \% \pm 20.8 \% \text { overall, while it was } \\
91.9 \% \pm 11.6 \% \text { in the IG (P=NS). } \\
\text { 3. } 51.5 \% \text { (CI } 34.4 \%-68.6 \% \text { ) of patients } \\
\text { controlled their hypertension in the } \\
\text { CG, and } 64.7 \% \text { (CI } 48.6 \%-80.8 \% \text { ) in } \\
\text { the IG controlled their hypertension } \\
\text { (P=NS). }\end{array}$ \\
\hline
\end{tabular}




\begin{tabular}{|c|c|c|c|c|c|c|}
\hline 2 & [12] & 22 & 52 & 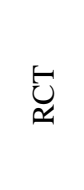 & $\begin{array}{l}\text { BP is observed, medicines are advised, } \\
\text { and instruction and alerts are generated } \\
\text { by SMS }\end{array}$ & $\begin{array}{l}\text { The BP monitoring and treatment system } \\
\text { provides services to the patients through } \\
\text { SMS text messages on their smartphones. } \\
\text { It is helpful, easy to use, adaptable, and } \\
\text { relevant for the patients. }\end{array}$ \\
\hline 3 & [13] & 50 & & 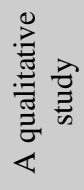 & & $\begin{array}{l}\text { Confidentiality, security, and flexibility } \\
\text { should be ensured so that the patients and } \\
\text { users engage with their devices and } \\
\text { encourage them to use, customize, and } \\
\text { personalize the healthcare applications. }\end{array}$ \\
\hline 4 & [14] & 63 & 36 & $\stackrel{U}{U}$ & $\begin{array}{l}\text { The system was developed to manage } \\
\text { two chronic diseases: high BP and high } \\
\text { blood glucose. The patients were } \\
\text { provided with both a BP and a glucose } \\
\text { sensor to monitor the vital signs and } \\
\text { provide information to the system, and } \\
\text { received reminders and alerts in } \\
\text { response. }\end{array}$ & $\begin{array}{l}\text { A significant decrease in mean systolic } \\
\text { BP from baseline ( } p<0.001) \text { was } \\
\text { observed in } 1 \text { month in the patients in the } \\
\text { IG. In the CG, the p-value was } 0.043 \\
\text { from baseline in } 3 \text { months. }\end{array}$ \\
\hline 5 & [15] & --- & 52 & U્ય & $\begin{array}{l}\text { Patients were provided medical } \\
\text { services in the IG, including clinic } \\
\text { appointments, prescriptions, advice, } \\
\text { medication pick-up schedules, } \\
\text { reminders, alerts, and BP-related } \\
\text { literature and education. All of the } \\
\text { services were provided through SMS } \\
\text { text messages. }\end{array}$ & $\begin{array}{l}\text { A systolic/diastolic BP of less than } \\
140 / 90 \mathrm{mmHg} \text { was observed. }\end{array}$ \\
\hline 6 & [16] & $\begin{array}{c}50 \\
\text { BP and } \\
\text { diabetes }\end{array}$ & 8 & 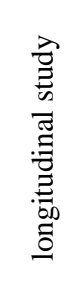 & $\begin{array}{l}\text { 1. System for patients to self-report } \\
\text { vital signs and symptoms like pulse } \\
\text { rate, BP, and lifestyle. } \\
\text { 2. The system sent reminders and } \\
\text { inspiration to the patients. } \\
\text { 3. The system also generated graphical } \\
\text { feedback of self-reports on patients' } \\
\text { mobile devices. }\end{array}$ & $\begin{array}{l}\text { The system helps reduce BP significantly } \\
\text { (systolic BP }-7 \mathrm{mmHg} \text {, diastolic BP }-4.9 \\
\mathrm{mmHg} \text { ) from baseline within a week if } \\
\text { used regularly. }\end{array}$ \\
\hline 7 & [17] & $\begin{array}{l}137 \mathrm{BP} \\
\text { and } \\
\text { Diabetes }\end{array}$ & 26 & $\underbrace{-1}_{\check{\simeq}}$ & $\begin{array}{l}\text { Mobile Application } \\
\text { The IG patients sent BP readings } \\
\text { measured by a sensor weekly to a } \\
\text { central server using a mobile phone } \\
\text { application. Management advice was } \\
\text { provided to the patient and their } \\
\text { physicians using a web application } \\
\text { based on the real-time data received. }\end{array}$ & $\begin{array}{l}\text { In the IG, the systolic BP of the patients } \\
\text { dropped significantly (mean } 95 \% \\
\text { confidence interval), (by } 6.5 \mathrm{mmHg} \text {; } \\
95 \% \mathrm{CI} 0.8 \text { to } 12.2 ; \mathrm{P}=0.027 \text { ), while in } \\
\text { the CG, it remained unchanged ( } 2.1 \text {; } \\
95 \% \mathrm{CI} 9.3 \text { to }-5.0 \text {; } \mathrm{P}=0.57 \text { ). } \\
\text { This study was conducted in the African } \\
\text { region, and the IG seemed to benefit } \\
\text { more. } \\
\text { It was observed the patients who } \\
\text { achieved a normal systolic BP of }<120 \\
\text { mmHg maintained a lower average blood } \\
\text { sugar than those with higher BP readings } \\
\text { (7.8 [SD 1.6] vs. } 8.9 \text { [SD } 2.2 \text { ] mmol/L; P } \\
=0.02 \text { ). }\end{array}$ \\
\hline
\end{tabular}




\begin{tabular}{|c|c|c|c|c|c|c|}
\hline 8 & [18] & 1372 & 52 & 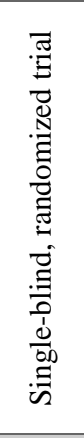 & $\begin{array}{l}\text { BP management system by } \\
\text { information-only and interactive SMS } \\
\text { text messaging. }\end{array}$ & $\begin{array}{l}\text { According to this study, information-only } \\
\text { SMS can adjust up to } 95 \% \text { CI in systolic } \\
\text { BP in } 12 \text { months, compared to usual care. } \\
\text { The BP that was }-2.2 \mathrm{mmHg}(-4.4 \text { to } \\
-0.04) \text { was adjusted to }-1.6 \mathrm{mmHg}(-3.7 \\
\text { to } 0.6) \text {. } \\
\text { Thus, in a patient with a BP }<140 / 90 \mathrm{~mm} \text {, } \\
\text { if using information-only SMS, the BP is } \\
\text { adjusted to } 1.42(1.03 \text { to } 1.95) \text {, while it is } \\
\text { adapted to } 1.41 \text { (1.02 to } 1.95) \text { for } \\
\text { interactive messaging compared to usual } \\
\text { care. }\end{array}$ \\
\hline 9 & [19] & 60 & -- & $\underset{\simeq}{E}$ & SMS & $\begin{array}{l}\text { Data analysis is the process of the two } \\
\text { pilot RCTs. }\end{array}$ \\
\hline 10 & [20] & 223 & 17 & 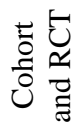 & $\begin{array}{l}\text { Self-reported health-related SMS } \\
\text { system used to improve knowledge } \\
\text { about health and behaviors }\end{array}$ & $\begin{array}{l}\text { In this study, no statistically significant } \\
\text { changes were observed in overall health } \\
\text { knowledge. }\end{array}$ \\
\hline 11 & [21] & 151 & 26 & 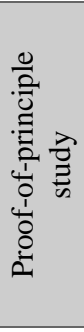 & $\begin{array}{l}\text { Mobile phone application supported } \\
\text { with health sensors }\end{array}$ & $\begin{array}{l}\text { Correlation between home measurements } \\
\text { and study center of } \mathrm{BP} \text { was high }(\mathrm{R}= \\
0.72 \text { for systolic } \mathrm{BP} \text { and } 0.72 \text { for diastolic } \\
\mathrm{BP} \text {, both } \mathrm{P}<0.001) \text {. } \\
\text { Better adherence }(71.4 \%) \text { was observed } \\
\text { in participants who were monitored } \\
\text { continuously compared with patients } \\
\text { who performed monthly measurements } \\
(64.3 \%, \mathrm{P}=.008) \text {. }\end{array}$ \\
\hline 12 & {$[22]$} & 50 & & & $\begin{array}{l}\text { Software on a mobile phone } \\
\text { Health measurements were taken in } \\
\text { two phases: pre-activated and post- } \\
\text { activated. }\end{array}$ & $\begin{array}{l}\text { A significant difference in adherence was } \\
\text { noted between the pre-activation and } \\
\text { post-activation phases, with p-values } \\
\text { of } .001 \text { and } .057 \text {, respectively. }\end{array}$ \\
\hline 13 & [23] & 49 & 8 & 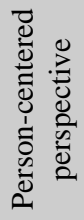 & Interactive mobile phone application & \\
\hline 14 & [24] & 200 & 6 & ب̂ & $\begin{array}{l}\text { Instead of SMS, automated and } \\
\text { interactive phone calls were made to } \\
\text { patients in the IG to obtain BP readings } \\
\text { and observe behavior changes. A home } \\
\text { BP unit was used to take } \\
\text { measurements. }\end{array}$ & $\begin{array}{l}\text { After automated phone calls, both of the } \\
\text { patient groups were observed at the time } \\
\text { of follow-up. The decrease in SPB was } \\
4.2 \mathrm{mmHg} \text { greater in the IG than in the } \\
\text { CG ( } 95 \% \text { CI }-9.1,0.7 ; \mathrm{p}=0.09) \text {. } \\
\text { The average decrease in systolic BP } \\
\text { (SBP) was } 8.8 \mathrm{mmHg}(-14.2 \text { to }-3.4, \mathrm{p}= \\
0.002) \text { in the IG. }\end{array}$ \\
\hline
\end{tabular}




\begin{tabular}{|c|c|c|c|c|c|c|}
\hline 15 & [25] & 285 & 26 & $\stackrel{E}{\mathscr{x}}$ & $\begin{array}{l}\text { In this proposed system, patients } \\
\text { monitored their body weight, BP, } \\
\text { and heart rate and sent these values } \\
\text { to the system in response to a } \\
\text { questionnaire over six months by } \\
\text { SMS. }\end{array}$ & $\begin{array}{l}\text { 1- At patients' final visits, the percentage } \\
\text { of control versus uncontrolled } \\
\text { hypertension was found to be } 31.7 \% \text { in } \\
\text { the IG and } 35.6 \% \text { in the CG ( } \mathrm{p}=0.47 \text { ). } \\
\text { 2- Decrease in systolic BP between initial } \\
\text { and final visits is } 15.5 \text { vs. } 11.9 \text { (p = } \\
\text { 0.13) and diastolic BP is } 9.6 \text { vs. } 4.4 \text { (p } \\
\text { = } 0.40 \text { ); } \\
\text { 3- Adherence to the system/protocol } \\
\text { within compliance levels of interest in } \\
\text { a real-life follow-up service: }>50 \% \\
\text { (84.8\% vs. } 73.3 \% \text { and }>25 \%(92.4 .8 \% \\
\text { vs. } 75.4 \% ; p=0.053) \text {. }\end{array}$ \\
\hline 16 & {$[26]$} & 65 & 4 & $\mathscr{E}$ & & $\begin{array}{l}\text { Non-significant improvements in } \\
\text { medication adherence at } 30 \text { days (M } \\
=.63 \text { and } 1.0 \text { points, respectively). Both } \\
\text { groups exhibited improved BP at } 30 \text { days } \\
(\mathrm{M}=-17.6 \text { and }-19.4 \mathrm{mmHg} \text { in systolic } \\
\mathrm{BP} \text { and } \mathrm{M}=-4.0 \text { and }-5.3 \mathrm{mmHg} \text { in } \\
\text { diastolic } \mathrm{BP} \text { for control and intervention } \\
\text { groups, respectively), but differences } \\
\text { between groups were not significant. }\end{array}$ \\
\hline 17 & [27] & 8 & & 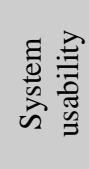 & Mobile application + system & $\begin{array}{l}\text { This shows that tele-management of BP } \\
\text { is also feasible in children and that this } \\
\text { system can improve and develop further } \\
\text { in the future. }\end{array}$ \\
\hline 18 & {$[28]$} & 100 & & 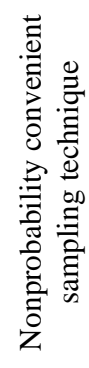 & $\begin{array}{l}\text { Mobile-based } \\
\text { interventions/usability }\end{array}$ & $\begin{array}{l}\text { In this study, } 88 \% \text { of the participants } \\
\text { were willing to use mobile-based health } \\
\text { intervention. Of the willing users, } 85.2 \% \\
\text { preferred receiving phone calls, while the } \\
\text { remaining } 14.8 \% \text { opted for the SMS } \\
\text { method. }\end{array}$ \\
\hline 19 & [29] & 28 & 8 & 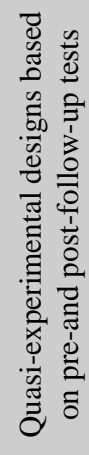 & $\begin{array}{l}\text { SMS + web application was used to } \\
\text { record the BP and bodyweight of the } \\
\text { patients in the IG every week. }\end{array}$ & $\begin{array}{l}\text { In the IG, a significant decrease ( } \mathrm{p}< \\
0.05) \text { in systolic and diastolic BP was } \\
\text { measured (-9.1 and }-7.2 \mathrm{mmHg} \text {, } \\
\text { respectively) at } 8 \text { weeks from the } \\
\text { baseline. } \\
\text { No improvement was observed in the } \\
\text { CG. }\end{array}$ \\
\hline 20 & [30] & 33 & 16 & 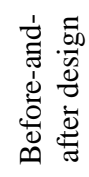 & $\begin{array}{l}\text { The mobile phone was used to receive } \\
\text { information and transmit measured BP } \\
\text { data }\end{array}$ & $\begin{array}{l}\text { In this 24-hour ambulatory pilot study, } \\
\text { overall control of BP was improved } \\
\text { significantly: BP was reduced by } 11 / 5 \text { (- } \\
13 / 7 \text { SD) mmHg (both P -0.001). }\end{array}$ \\
\hline
\end{tabular}




\begin{tabular}{|c|c|c|c|c|c|c|}
\hline 21 & [31] & 50 & & 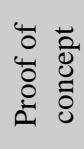 & $\begin{array}{l}\text { They Developed a kit for pregnant } \\
\text { women consisting of a BP sensor } \\
\text { connected to a mobile phone through } \\
\text { Bluetooth. }\end{array}$ & $\begin{array}{l}90 \% \text { of the women consented to use this } \\
\text { kit, and } 78 \% \text { preferred to use the home } \\
\text { testing model. }\end{array}$ \\
\hline 22 & [32] & 95 & 26 & $\underset{\widetilde{U}}{\mathscr{U}}$ & $\begin{array}{l}\text { The effects of a mobile self-monitoring } \\
\text { program on patient behavior, BP } \\
\text { control, and medication adherence were } \\
\text { observed. }\end{array}$ & $\begin{array}{l}\text { Improvement in BP control was } \\
\text { beta=0.04 }(\mathrm{P}=.02) \text {, where systolic BP } \\
\text { was beta }=-0.27(\mathrm{P}=.02) \text {, and diastolic } \mathrm{BP} \\
\text { was beta }=-0.34(\mathrm{P}=.007) \text { in } 6 \text { months. No } \\
\text { improvement in medication adherence } \\
\text { was observed. }\end{array}$ \\
\hline
\end{tabular}

It was found that the overall effect of using mobile health technology to improve the management of hypertension is positive. In this survey, 11 randomized control trials were considered relevant based on their outcomes, which help to raise awareness about the topic. Detail discussions are provided in the next section.

\section{Discussion}

This systematic review has identified various adopted approaches and outcomes obtained using mobile technology intervention to manage hypertension. Firstly, most of the studies used RCTs to collect and analyze the data. Other methods are randomized cluster, the proof of concept, quasi-experimental, non-probability and longitudinal analysis, etc. Only one qualitative study [13] was identified in this review. Hence we found a significant research gap in this (quantitative method of data collection) area.

Using mobile technologies for managing hypertension involves patient's social entities as well. As a result, various factors may influence the use of mobile applications, including users' technology skills and competence, knowledge and awareness of hypertension, attitudes toward technology and mobile applications, behavioral implications, and users' acceptance of mobile technologies or applications. Most of these can be related to psychological, behavioral, and awareness factors. Qualitative methods may be appropriate for the practical analysis of such attributes. They can elicit a better interpretation of the participant's thoughts and opinions than quantitative methods, which may not address such details. Therefore, methodological gaps in the studies on the impact of mobile technologies in managing hypertension are evident from this systematic review. Furthermore, this survey also suggested mixed methods (qualitative and quantitative) of study need to be more focused in the future.

Secondly, we found that only 8 of the 22 studies had a sample size of more than 100 participants. As a result, the findings may not apply to a larger population and limits it to a generalized fact in managing hypertension. In addition, flawed analysis between people in different regions, of various socioeconomic statuses, across age groups, and other health complications also limits the scope of findings. Only four studies [16], [17], [28], and [30] are identified, which included the patient having both hypertensive and diabetes complications. Two studies [5] and [29] included hypertensive and obese patients. Only one study [31] was found to consider hypertensive patients having preeclampsia. Still, lifestyle changes such as diet control and physical activities (walking, exercise, yoga, etc.) were not tracked and correlated with the changes in hypertension. 
Furthermore, hypertension can be associated with other factors, such as stress, depression, and socioeconomic and cultural factors. This survey concluded that many other parameters about the applicant must be included in the study to understand well the effect of mobile technology-based interventions to manage hypertension. However, this systematic review has revealed significant gaps in the inclusion of various influencing factors in the studies identified.

Regarding the types of interventions used in the studies reviewed, diverse approaches were observed. Several studies [12], [15], [18]-[20], [24], [25], [28], [29] relied basically on SMS text messages. Mobile technologies have rapidly developed in the past few decades. Various advanced features are now available in mobile phones, including a wide range of mobile applications, internet browsing, high-resolution cameras, fingerprint, face recognition, eye tracking, and much more. The number of smartphone users globally has increased from 2.7 billion to 2.9 billion in 2018 and 3.2 billion in 2019; it is estimated to reach 3.8 billion in 2021. In addition, smartphones can be integrated with communication technologies such as Bluetooth or other similar devices to enable remote diagnosis and monitoring of various complications, like diabetes and hypertension. It can be observed in [17] that wireless connections are established between smartphones, blood pressure and diabetes monitoring devices using Bluetooth technology. In this study, the readings were transferred from the diagnostic devices to the smartphone applications and were then shared with the hospital's servers by the installed mobile applications. The data from the hospital servers can be accessed by the staff nurses and doctors, who can monitor the patients remotely and provide feedback or medication through the application if necessary. Similar interventions were identified in other studies [27], [31], [32], revealing that the number of studies focusing on integrating mobile technology with diagnosis/diagnostic and monitoring systems to deliver healthcare services remotely is increasing. In addition, several other studies [14], [15], [17], [22] focused on providing educational resources and information related to healthcare and self-management practices, as well as channels for booking appointments. Therefore, mobile technologies to manage hypertension can be used to create awareness, promote selfmanagement practices, enable remote monitoring and diagnosis, reduce healthcare costs (travel), and improve flexibility and ease in accessing healthcare services.

Almost all the studies reported positive outcomes. However, depending on the nature of the study, some differences in the findings were observed. There were no significant differences in the compliance rate between the intervention and control groups [11]. According to [12], [14]-[16], [18], [21], [24]-[26], the percentage of participants whose BP was controlled at the end of the study was higher belongs to the intervention group as compared to the participants in the control group. The BP assessment was taken at the end of the intervention, and significant blood pressure reductions were observed in the intervention group. However, differences in the types of intervention led to different results. For instance, in [8], the reduction in blood pressure was more significant among patients who were provided with interactive SMS than in patients who were offered information-only SMS. Thus, the study revealed that only one-sided communication or providing information may not be as effective as two-sided communication or giving information along with help, such as feedback.

Similarly, in [19], it was found that measurements at the health study conducted in the center and at patients' homes differed. It is also observed that the patients with semi-monthly measurements fared better than patients with monthly measurements. The study has indicated that regular and more frequent assessments can deliver better results than less 
frequent measurements. Significant reductions in patients' blood pressure readings are evident from the follow-up intervention in [22]. However, medical technology-based interventions such as text messages and reminders may not be effective in all contexts compared to more interactive technologies. This aspect can be observed in [24], in which no significant differences were identified between the intervention and control groups, while reductions in blood pressure were identified in both groups.

Several other studies have adopted different approaches for evaluation and have obtained some interesting results. For instance, in [10], SMS text-based intervention was found to be effective in reducing patients' blood pressure. A qualitative study [13] has identified that flexibility, security, privacy, and customizability, among other factors, were influential in engaging patients using mobile health care systems for controlling blood pressure. Similarly, in [15], mobile intervention technologies helped in the self-management of both diabetes and hypertension at home, with significant reductions in blood pressure and improved control of blood sugar levels. As previously discussed, information-only SMS interventions (education and information) did not significantly impact managing hypertension. Accordingly, in [18], no significant difference in patients' healthcare knowledge was observed at the end of the study. However, interventions that used more advanced technologies, such as interactive mobile applications with diagnosis, consultation, and treatment features, were found to be more effective in reducing patients' blood pressures. Furthermore, the studies [22], [23], [27], [28] were conducted/reviewed just to increase the awareness about self-management practices and healthcare information. Therefore it is inferred that interactivity, experience, usability, privacy, and security concerns have resulted in better acceptance from patients and significantly reduced blood pressure.

Thus, it can be concluded that there are gaps in the methodologies, intervention types, and contexts of the studies reviewed. Nonetheless, it was determined that user acceptance was higher with more interactive and flexible mobile applications and their integration with other technologies. It has a more significant impact on managing hypertension, self-management procedures, and healthcare awareness.

In addition, the findings from this study have both theoretical and practical implications. We have identified the gaps in the research related to the impact of mobile technologies on managing hypertension. Addressing these gaps, such as limited sample sizes and limited behavioral analysis, can be used as the basis for future research. This review also provided a comprehensive view of the research related to m-health and its impact on managing hypertension, which can be a source of key information for both academic and industry/Industrial practitioners. Moreover, the findings from the review can help industry/industrial practitioners develop more flexible and interactive mobile health technologies and address issues such as privacy and security. Finally, it is identified in this review that an integrated mobile application providing services such as consultation, diagnosis, report management, treatment, education, and awareness can improve the interactivity, flexibility, and usability of mobile health systems in managing hypertension. All the suggestions are provided in tabular form in Table 2. 
Table 2. Author observation and recommendations

\begin{tabular}{|c|c|c|}
\hline$\#$ & Observations & Suggestions / recommendations \\
\hline 1 & $\begin{array}{l}\text { Qualitative methods may be appropriate for } \\
\text { the practical analysis of such attributes. They } \\
\text { can elicit a better interpretation of the } \\
\text { participant's thoughts and opinions than } \\
\text { quantitative methods, which may not address } \\
\text { such details. }\end{array}$ & $\begin{array}{l}\text { This survey also suggested mixed methods } \\
\text { (qualitative and quantitative) of study need } \\
\text { to be more focused in the future }\end{array}$ \\
\hline 2 & $\begin{array}{l}\text { A shorter sample size (100 to } 500 \text { patients) is } \\
\text { observed in most of the studies which } \\
\text { restricts the finding to be generalized. }\end{array}$ & Reasonably larger sample size is required \\
\hline 3 & $\begin{array}{l}\text { In most of the studies, participants are related } \\
\text { to the same region and age group. }\end{array}$ & $\begin{array}{l}\text { Analysis of patients in different regions, of } \\
\text { various socioeconomic statuses, across age } \\
\text { groups, and other health complications } \\
\text { require to get more realistic findings. }\end{array}$ \\
\hline 4 & $\begin{array}{l}\text { In most of the studies management of a } \\
\text { single disease is observed }\end{array}$ & $\begin{array}{l}\text { We recommend future studies to observe the } \\
\text { effect of mobile applications on managing } \\
\text { multiple health problems because in most } \\
\text { cases they are interconnected }\end{array}$ \\
\hline 5 & $\begin{array}{l}\text { In most of the applications on hypertension is } \\
\text { monitored and try to control using the mobile } \\
\text { application but other related factors are } \\
\text { ignored }\end{array}$ & $\begin{array}{l}\text { Hypertension can be associated with other } \\
\text { factors, such as stress, depression, and } \\
\text { socioeconomic and cultural factors. We } \\
\text { recommend including these factors in the BP } \\
\text { management mobile application. }\end{array}$ \\
\hline 6 & $\begin{array}{l}\text { Mostly conventional ways are used to } \\
\text { sensing and monitoring health parameters. }\end{array}$ & $\begin{array}{l}\text { Modern mobile technologies including } \\
\text { internet browsing, high-resolution cameras, } \\
\text { fingerprint, face recognition, eye tracking, } \\
\text { NFC, Bluetooth, GPS, etc. also be used for } \\
\text { better results }\end{array}$ \\
\hline 7 & $\begin{array}{l}\text { It is also observed that the patients with } \\
\text { semi-monthly measurements fared better } \\
\text { than patients with monthly measurements }\end{array}$ & $\begin{array}{l}\text { Considering the modern communication } \\
\text { tools more frequent even real-time } \\
\text { measurement is possible and can be applied } \\
\text { if required }\end{array}$ \\
\hline 8 & $\begin{array}{l}\text { SMS text-based intervention was found to be } \\
\text { more effective in reducing patients' blood } \\
\text { pressure }\end{array}$ & $\begin{array}{l}\text { Other modern intervention methods like } \\
\text { interactive mobile applications, live calls, or } \\
\text { chats also need to be tested }\end{array}$ \\
\hline
\end{tabular}

\section{Conclusion}

In this study, we examined the impact of mobile phone technologies on hypertension treatment. We reviewed 23 different pilot studies and analyzed them to highlight their findings and identify their shortcomings. In addition, new targets and recommendations are made for future studies to address these shortcomings. We found that mobile technology has played a vital role in hypertension management. Self-assessment and reporting of BP measurements through mobile phone technology (text messages, phone calls, and applications) proved an excellent way to maintain normal BP. 
It will also reduce the burden on healthcare facilities and will help practitioners diagnose and make treatment plans conveniently. The mobile applications can be used to send prescriptions, medication plans, medicine tracking/tuning, reminders, warnings, follow-up reminders, appointment schedules, guidelines, etc., to the patient and increase awareness about the disease. These applications can also help estimate the future trends of disease in society.

Nonetheless, we identified some limitations and weaknesses in the analyzed studies; for example, most have insufficient sample sizes (the number of participants was less than 100), lesser input parameters, and weak communication with patients. Based on these shortcomings, we have provided some suggestions for future research. Firstly, these kinds of studies should be conducted on a larger scale and take into account different cultures to improve the generalizability of the findings. Secondly, other factors that affect BP, such as obesity, diabetes, eating habits, working environment, and daily workout, should also be noted down. Finally, patient behavior and lifestyle are critical for this purpose and should be measured on regular basis, as monitoring only vital signs are insufficient. This survey proved a fair analysis of existing mobile hypertension management studies and their pros and cons and identified the gaps that exist in the research study and are expected to cover with the passage of time and advancement in technologies.

\section{Acknowledgment}

This research has been sponsored by the Sensor Networks and Cellular Systems (SNCS) Research Center and Deanship of Scientific Research at the University of Tabuk Saudi Arabia, under project No. 002/1442H.

\section{References}

[1] W. H. Organization, “Hypertension,” 2020. [Online]. Available: https://www.who.int/healthtopics/hypertension/\#tab=tab_1. [Accessed: 19-Jan-2021].

[2] WHO, "Noncommunicable diseases: Risk factors," 2016. [Online]. Available: https://www.who.int/data/gho/data/themes/topics/topic-details/GHO/ncd-risk-factors. [Accessed: 19-Jan-2021].

[3] A. Aldiab et al., "Prevalence of hypertension and prehypertension and its associated cardioembolic risk factors; a population based cross-sectional study in Alkharj, Saudi Arabia," BMC Public Health, vol. 18, no. 1, p. 1327, Dec. 2018. Article (CrossRef Link)

[4] I. S. of Hypertension, "ISH Global Hypertension Practice Guidelines," 2016. [Online]. Available: https://ish-world.com/news/a/ISHGPG/. [Accessed: 19-Jan-2021].

[5] C. El Bcheraoui et al., "Hypertension and Its Associated Risk Factors in the Kingdom of Saudi Arabia, 2013: A National Survey," Int. J. Hypertens., vol. 2014, pp. 1-8, 2014. Article (CrossRef Link)

[6] D. Mulvaney et al., "Development of m-health monitoring systems in India and Iraq," in Proc. of 2012 Annual International Conference of the IEEE Engineering in Medicine and Biology Society, pp. 288-291, 2012. Article (CrossRef Link)

[7] M. M. Baig, H. GholamHosseini, J. Gutierrez, E. Ullah, and M. Lindén, "Early Detection of Prediabetes and T2DM Using Wearable Sensors and Internet-of-Things-Based Monitoring Applications," Appl. Clin. Inform., vol. 12, no. 01, pp. 001-009, Jan. 2021. Article (CrossRef Link)

[8] P. Olla and J. Tan, Eds., Mobile Health Solutions for Biomedical Applications, IGI Global, 2009. Article (CrossRef Link) 
[9] F. M. Al-Anezi, "Potential Benefits and Challenges Associated with the Adoption of Mobile health (m-health) in Kingdom of Saudi Arabia," in Proc. of 19th International Symposium on Distributed Computing and Applications for Business Engineering and Science (DCABES), pp. 323-327, 2020. Article (CrossRef Link)

[10] M. M. Alotaibi, R. Istepanian, and N. Philip, "A mobile diabetes management and educational system for type-2 diabetics in Saudi Arabia (SAED)," mHealth, vol. 2, pp. 33-33, Aug. 2016. Article (CrossRef Link)

[11] E. Márquez Contreras et al., "Eficacia de una intervención informativa a hipertensos mediante mensajes de alerta en el teléfono móvil (HTA-ALERT)," Atención Primaria, vol. 34, no. 8, pp. 399-405, 2004.Article (CrossRef Link)

[12] N. Leon, R. Surender, K. Bobrow, J. Muller, and A. Farmer, "Improving treatment adherence for blood pressure lowering via mobile phone SMS-messages in South Africa: a qualitative evaluation of the SMS-text Adherence SuppoRt (StAR) trial," BMC Fam. Pract., vol. 16, no. 1, p. 80, Dec. 2015. Article (CrossRef Link)

[13] L. Glynn, M. Casey, J. Walsh, P. S. Hayes, R. P. Harte, and D. Heaney, "Patients' views and experiences of technology based self-management tools for the treatment of hypertension in the community: A qualitative study," BMC Fam. Pract., vol. 16, no. 1, p. 119, Dec. 2015. Article (CrossRef Link)

[14] C. Or and D. Tao, "A 3-Month Randomized Controlled Pilot Trial of a Patient-Centered, Computer-Based Self-Monitoring System for the Care of Type 2 Diabetes Mellitus and Hypertension," J. Med. Syst., vol. 40, no. 4, p. 81, Apr. 2016. Article (CrossRef Link)

[15] K. Bobrow et al., "Efficacy of a text messaging (SMS) based intervention for adults with hypertension: protocol for the StAR (SMS Text-message Adherence suppoRt trial) randomized controlled trial," BMC Public Health, vol. 14, no. 1, p. 28, 2014. Article (CrossRef Link)

[16] U. Bengtsson, K. Kjellgren, I. Hallberg, M. Lindwall, and C. Taft, "Improved Blood Pressure Control Using an Interactive Mobile Phone Support System,” J. Clin. Hypertens., vol. 18, no. 2, pp. 101-108, Feb. 2016. Article (CrossRef Link)

[17] K. A. Earle, R. S. H. Istepanian, K. Zitouni, A. Sungoor, and B. Tang, "Mobile Telemonitoring for Achieving Tighter Targets of Blood Pressure Control in Patients with Complicated Diabetes: A Pilot Study," Diabetes Technol. Ther., vol. 12, no. 7, pp. 575-579, Jul. 2010. Article (CrossRef Link)

[18] K. Bobrow et al., "Mobile Phone Text Messages to Support Treatment Adherence in Adults With High Blood Pressure (StAR): A Single-Blind, Randomized Trial," Circulation, vol. 133, pp. 592600, 2016. Article (CrossRef Link)

[19] L. R. Buis, N. T. Artinian, L. Schwiebert, H. Yarandi, and P. D. Levy, "Text Messaging to Improve Hypertension Medication Adherence in African Americans: BPMED Intervention Development and Study Protocol," JMIR Res. Protoc., vol. 4, no. 1, p. e1, Jan. 2015. Article (CrossRef Link)

[20] D. Hacking, H. J. Haricharan, K. Brittain, Y. K. Lau, T. Cassidy, and M. Heap, "Hypertension Health Promotion via Text Messaging at a Community Health Center in South Africa: A Mixed Methods Study," JMIR mHealth uHealth, vol. 4, no. 1, p. e22, Mar. 2016. Article (CrossRef Link)

[21] L. W. Wijsman, E. Richard, R. Cachucho, A. J. de Craen, S. Jongstra, and S. P. Mooijaart, "Evaluation of the Use of Home Blood Pressure Measurement Using Mobile Phone-Assisted Technology: The iVitality Proof-of-Principle Study," JMIR mHealth uHealth, vol. 4, no. 2, p. e67, Jun. 2016. Article (CrossRef Link)

[22] S. Patel et al., "Mobilizing Your Medications: An Automated Medication Reminder Application for Mobile Phones and Hypertension Medication Adherence in a High-Risk Urban Population," $J$. Diabetes Sci. Technol., vol. 7, no. 3, pp. 630-639, May 2013.

[23] I. Hallberg, A. Ranerup, and K. Kjellgren, "Supporting the self-management of hypertension: Patients' experiences of using a mobile phone-based system," J. Hum. Hypertens., vol. 30, no. 2, pp. 141-146, Feb. 2016. Article (CrossRef Link) 
[24] J. D. Piette et al., "Hypertension Management Using Mobile Technology and Home Blood Pressure Monitoring: Results of a Randomized Trial in Two Low/Middle-Income Countries," Telemed. e-Health, vol. 18, no. 8, pp. 613-620, Oct. 2012. Article (CrossRef Link)

[25] M. P. Carrasco et al., "Impact of Patient-General Practitioner Short-Messages-Based Interaction on the Control of Hypertension in a Follow-up Service for Low-to-Medium Risk Hypertensive Patients: A Randomized Controlled Trial," IEEE Trans. Inf. Technol. Biomed., vol. 12, no. 6, pp. 780-791, Nov. 2008. Article (CrossRef Link)

[26] L. Buis et al., "Abstract 20109: Impact of Text Message Medication Reminders on Medication Adherence and Blood Pressure in a High Risk Urban Emergency Department Population," Circulation, vol. 130, 2014.

[27] C. S. Pruette, J. J. Fadrowski, M. Bedra, and J. Finkelstein, "Feasibility of a mobile blood pressure telemanagement system in children with hypertension," in Proc. of 2013 IEEE Point-ofCare Healthcare Technologies (PHT), pp. 188-191, 2013. Article (CrossRef Link)

[28] M. Siddiqui et al., "Assessing acceptability of hypertensive/diabetic patients towards mobile health based behavioral interventions in Pakistan: A pilot study," Int. J. Med. Inform., vol. 84, no. 11, pp. 950-955, Nov. 2015. Article (CrossRef Link)

[29] M.-J. Park, H.-S. Kim, and K.-S. Kim, "Cellular phone and Internet-based individual intervention on blood pressure and obesity in obese patients with hypertension," Int. J. Med. Inform., vol. 78, no. 10, pp. 704-710, Oct. 2009. Article (CrossRef Link)

[30] A. LOGAN et al., "Mobile Phone-Based Remote Patient Monitoring System for Management of Hypertension in Diabetic Patients," Am. J. Hypertens., vol. 20, no. 9, pp. 942-948, Sep. 2007. Article (CrossRef Link)

[31] R. Ganapathy, A. Grewal, and J. S. Castleman, "Remote monitoring of blood pressure to reduce the risk of preeclampsia related complications with an innovative use of mobile technology," Pregnancy Hypertens. An Int. J. Women's Cardiovasc. Heal., vol. 6, no. 4, pp. 263-265, Oct. 2016. Article (CrossRef Link)

[32] J. Y. Kim, N. E. Wineinger, and S. R. Steinhubl, "The Influence of Wireless Self-Monitoring Program on the Relationship Between Patient Activation and Health Behaviors, Medication Adherence, and Blood Pressure Levels in Hypertensive Patients: A Substudy of a Randomized Controlled Trial," J. Med. Internet Res., vol. 18, no. 6, p. e116, Jun. 2016. Article (CrossRef Link) 


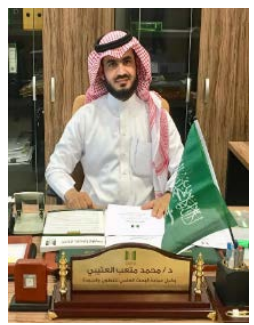

MOHAMMED ALOTAIBI received the B.S. in computer Science from King Saud University in July 2008 and M.S. degrees in Computer and Information Networks, Essex University, UK (Jan, 2011)., respectively He got Ph.D. in health informatics from Kingston University London in March 2015. He has served as assistant Prof and then associate prof at the faculty of computers and information technology at the University of Tabuk since August 2015 until now. He owned three research project funds from different organizations. $\mathrm{He}$ is now a research leader of a research group that focus on using robotic and AI in chronic diseases which owned a research fund worth 100.000 Saudi riyals.

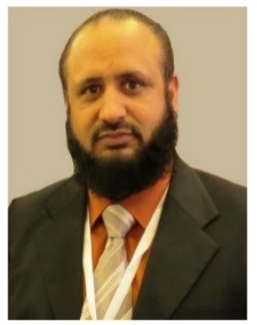

MOHAMMAD AMMAD UDDIN receives his Ph.D. degree from ENSTA Bretagne France in wireless sensors network, MS in computer networks from COMSATS Institute of Information Technology Islamabad Pakistan, and M.Sc. of computer sciences in Software Engineering from Bahria University Islamabad Pakistan. He is CCNA \& CCAI Certified and currently is a Senior Researcher at the Sensor Networks and Cellular Systems Research Centre University of Tabuk Kingdome of Saudi Arabia. He taught many graduate and undergraduate computer courses in several universities in the Kingdom and abroad. He led many research and development projects in the area of wireless sensor networks, underwater sensor networks, and smart agriculture. He is the author of many research papers published in IEEE and other journals. He is listed as an Inventor in a patent registered in the USA. His research area includes routing, clustering, and localization of sensors nodes in wireless sensor networks. 